\title{
Dependence of the maximal lactate steady state on the motor pattern of exercise
}

\author{
R Beneke, R M Leithäuser, M Hütler
}

\begin{abstract}
Background-Blood lactate concentration (BLC) can be used to monitor relative exercise intensity. The highest BLC representing an equilibrium between lactate production and elimination is termed maximal lactate steady state (MLSS). MLSS is used to discriminate qualitatively between continuous exercise, which is limited by stored energy, from other types of exercise terminated because of disturbance of cellular homoeostasis.
\end{abstract}

Aim-To investigate the hypothesis that MLSS intraindividually depends on the mode of exercise.

Methods-Six junior male rowers (16.5 (1.4) years, $181.7(3.1) \mathrm{cm}, 69.8(3.3) \mathrm{kg}$ ) performed incremental and constant load tests on rowing and cycle ergometers. Measurements included BLC, sampled from the hyperaemic ear flap, heart rate, and oxygen uptake. MLSS was defined as the highest BLC that increased by no more than $1.0 \mathrm{mmol} / 1$ during the final 20 minutes of constant workload.

Results-In all subjects, MLSS was lower $(p \leqslant 0.05)$ during rowing $(2.7(0.6) \mathrm{mmol} / \mathrm{l})$ than during cycling $(4.5(1.0) \mathrm{mmol} / 1)$. No differences between rowing and cycling were found with respect to MLSS heart rate $(169.2(9.3) v 172.3(6.7)$ beats/min), MLSS workload (178.7 (29.8) $v 205.0$ (20.7) W), MLSS intensity expressed as a percentage $(63.3(6.6) \% v 68.6(3.8) \%)$ of peak workload $(280.8(15.9) v 299.2(28.4) \mathrm{W})$ or percentage $(76.4(3.4) \% v 75.1(3.0) \%)$ of peak oxygen uptake (60.4 (3.4) $v 57.2(8.6)$ $\mathrm{ml} / \mathrm{kg} / \mathrm{min}$ ).

Conclusions-In rowing and cycling, the MLSS but not MLSS workload and MLSS

Sports Medicine, Free University, Berlin, Germany R Beneke

M Hütler

Rehabilitationsklinik Elbe-Saale, Barby, Germany

$\mathrm{R}$ Beneke

xx-well.com AG,

Berlin

R Beneke

LMC Laboratory,

Berlin

R M Leithäuser

Correspondence to: Dr Beneke, Brauhofstr 1, 10587 Berlin, Germany rabe94@zedat.fu-berlin.de

Accepted 16 February 2001 without continuous blood lactate accumulasive endurance training normally lasting 20-60 tion. ${ }^{58}$ MLSS intensity corresponds to inten- minutes and is considered to discriminate qualitatively between training methods in which continuous exercise is limited by stored energy from others which have to be terminated because of disturbance of cellular homoeostasis.

In top athletes performing their specific type of exercise, MLSS was found to be interindividually different. ${ }^{2}$ The latter study was performed on the basis of the fact that specific training sessions resulted in BLCs that obviously differed from generally expected values. ${ }^{3910}$ However, a comparison of top athletes performing their specific exercises cannot effectively discriminate between effects related to specific tasks, personal factors, and/or possible complex adaptations to a long lasting training process.

The hypothesis that the MLSS depends on the specific task itself was investigated by an intraindividual analysis of rowing and cycling ergometry in junior athletes who were able to perform, and were used to performing, both rowing and cycling on a regular basis but were not highly specialised top athletes.

\section{Methods}

SUBJECTS AND PROCEDURES

The intraindividual comparison of MLSS in rowing and cycling was conducted in six junior male rowers (age 16.5 (1.4) years; height 181.7 (3.1) $\mathrm{cm}$; body mass 69.8 (3.3) kg; means (SD)) of regional or national level. They had carried out $6-10$ hours of systematic training a week for 1-2 years, including specific training in a boat and on a rowing ergometer and nonspecific exercises such as cycling, running, and power lifting. The test period was during the winter when training in a boat was the exception because of weather conditions. No subject was receiving pharmacological or dietetic treatment. Informed consent was obtained after explanation of the nature and risks involved in participation in the experiments, which conformed to internationally accepted policy statements regarding the use of human subjects.

EXERCISE TESTING

The subjects performed incremental and constant load tests on a rowing ergometer (Gjessing; Empacher, Eberbach, Germany) with a brake load of $27 \mathrm{~N}$ and on a cycle ergometer (Elema Schönander 380, Siemens, Germany). All tests were conducted at similar times in the afternoon on separate days at least two hours after a light meal. Time between separate testing sessions was $48-72$ hours. The subjects were instructed not to engage in strenuous activity during the day before an exercise test. 
ERGOMETRY

The initial rowing ergometer workload was 145 $\mathrm{W}$ and was increased by $35 \mathrm{~W}$ every three minutes. After every work stage, the test was interrupted by a 30 second break for blood sampling. The cycle ergometer test started with $100 \mathrm{~W}$ and was increased by $50 \mathrm{~W}$ every third minute. Blood sampling was conducted at the end of every work stage. All incremental load tests were finished at individual maximal power outputs indicated by volitional fatigue after strong vocal encouragement.

All constant load tests lasted 30 minutes except those that were terminated because of volitional fatigue. In rowing, the stroke frequency was 25-32 strokes/min. Cycle ergometry was performed with individual constant pedalling rates of at least $90 / \mathrm{min}$. According to a previous procedure, ${ }^{2}$ the first constant workload corresponded to a BLC of $2.0-2.5 \mathrm{mmol} / 1$ measured during the incremental load test in rowing. In cycle ergometry, the analogous BLC was $4.0 \mathrm{mmol} / \mathrm{l}$. Constant load tests with $5-10 \%$ higher or lower workloads were conducted on subsequent days until MLSS was verified. This resulted in seven to 12 constant load tests per subject. MLSS was defined as the highest BLC that increased by no more than $1.0 \mathrm{mmol} / 1$ during the final 20 minutes of a constant workload. The MLSS was calculated as the mean BLC measured at 15,20,25, and 30 minutes of the MLSS workload. ${ }^{11}$

BLOOD LACTATE CONCENTRATION

Capillary blood samples $(20 \mu \mathrm{l})$ were taken from the hyperaemic ear flap (Finalgon forte, Thomae, Biberach, Germany). During incremental load tests, blood was drawn before the test and at the end of each stage. During the constant load tests, the BLC was measured before and at the end of every 5 th minute. The BLC was analysed by an enzymatic photometric method (Boehringer, Mannheim, Germany). Coefficients of variation for repeat analyses of identical samples were less than $5 \% .^{12}$

HEART RATE

Heart rate was monitored continuously throughout all tests (Sport tester PE 3000; Polar, Oy; Finland). Data corresponding to the time of blood sampling were analysed.

OXYGEN UPTAKE

Oxygen uptake was determined with a portable spirometric system (K2; Cosmed, Rome, Italy) in 15 second intervals. Before each test, the device was calibrated according to the manufacturer's instructions. The coefficient of reliability for oxygen uptake measurements with such a system has been reported to be about 0.99. ${ }^{13}$ Compared with other methods of measuring oxygen uptake, the K2 showed similar $^{1314}$ or slightly lower values of oxygen uptake at levels above $2.71 / \mathrm{min} .^{15}$

METABOLIC POWER AND MECHANICAL EFFICIENCY According to a previously published procedure, ${ }^{16}$ the net metabolic power was calculated as follows: metabolic power $(\mathrm{W})=$ oxygen uptake above rest $(\mathrm{ml} / \mathrm{s}) \times$ caloric equivalent $(\mathrm{J} / \mathrm{ml})+$ net lactate production $(\mathrm{mmol} / \mathrm{l} / \mathrm{s}) \times$ oxygen-lactate equivalent $(\mathrm{ml} / \mathrm{kg} / \mathrm{mmol}) \times$ body mass $(\mathrm{kg}) \times$ calorific equivalent $(\mathrm{J} / \mathrm{ml})$.

Oxygen-lactate equivalent and calorific equivalent were set to $3.0 \mathrm{ml} / \mathrm{mmol} / \mathrm{kg}^{17}$ and $21.131 \mathrm{~J} / \mathrm{ml} .{ }^{18}$ Mechanical efficiency was calculated from mechanical power per metabolic power times 100 .

STATISTICAL ANALYSIS

Data are reported as mean (SD). Differences within subjects were determined by the Wilcoxon test. Relations between variables were examined by linear regression analysis. For all statistics, the significance level was set at $\mathrm{p} \leqslant 0.05$.

\section{Results}

In all subjects, MLSS was lower $(p \leqslant 0.05)$ during rowing $(2.7(0.6) \mathrm{mmol} / \mathrm{l})$ than during cycling (4.5 (1.0) mmol/l) (fig 1). No difference $(p>0.05)$ was found between rowing and cycling with respect to the workload identified to result in MLSS (178.7 (29.8) v 205.0 (20.7) W). No BLC steady state was observed at constant workloads about $5.5 \%$ higher than MLSS workloads in rowing and cycling (fig 2).

Oxygen uptake at MLSS (46.2 (4.0) $v 43.0$ (7.0) $\mathrm{ml} / \mathrm{kg} / \mathrm{min}$ ) and heart rate at MLSS (169.2 (9.3) v 172.3 (6.7) beats/min) were not different in rowing and cycling $(\mathrm{p}>0.05)$. Also the corresponding relative exercise intensities expressed as a percentage (63.3 (6.6)\% $v 68.6$ $(3.8) \%)$ of peak workload (280.8 (15.9) v $299.2(28.4) \mathrm{W})$ or percentage $(76.4(3.4) \% v$ $75.1(3.0) \%)$ of peak oxygen uptake (60.4 (3.4)

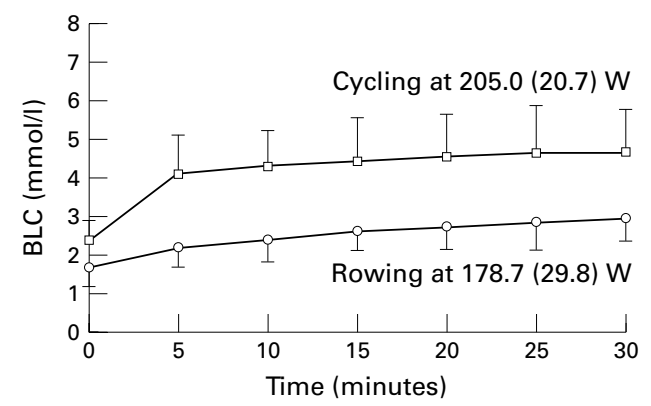

Figure 1 Blood lactate concentration (BLC) response to maximal lactate steady state workload in rowing and cycle ergometry.

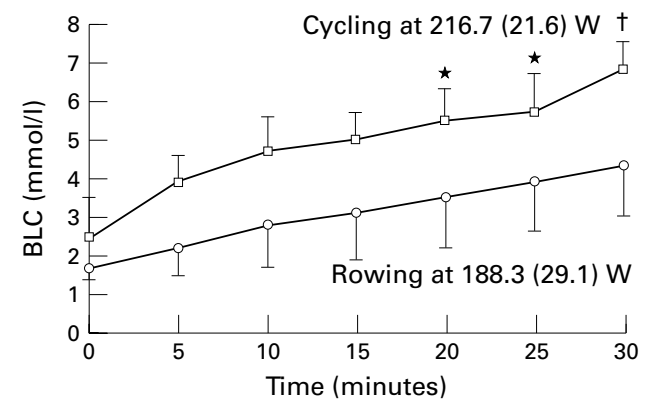

Figure 2 Blood lactate concentration (BLC) response to relative workload intensities about $5.5 \%$ higher than maximal lactate steady state workload in rowing and cycle ergometry. In cycling, only five subjects were able to continue for 25 minutes $(*)$ and four subjects were able to cycle for 30 minutes $(t)$. 


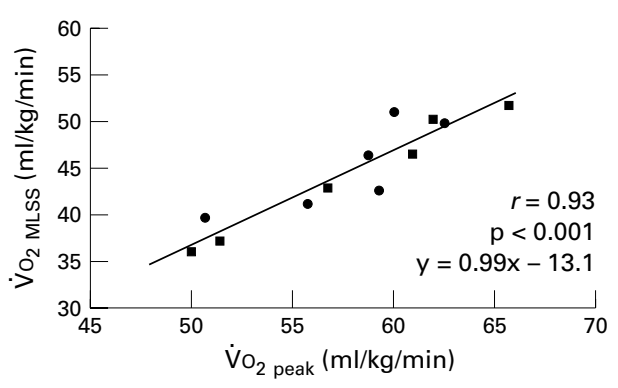

Figure 3 Correlation between maximal lactate steady state (MLSS) $\dot{V}_{2}$ and peak $\dot{V}_{O_{2}}$ in rowing and cycle ergometry.

v $57.2(8.6) \mathrm{ml} / \mathrm{kg} / \mathrm{min}$ ) were not different in rowing and cycling $(p>0.05)$. Peak BLC reached after termination of the incremental load test did not differ significantly between rowing (11.1 (2.3) mmol/l) and cycling (10.0 (1.8) $\mathrm{mmol} / \mathrm{l}$ ). Consequently the values of metabolic power at MLSS workload and at peak workload of 1016 (113) W and 1595 (270) W in rowing and of 938 (165) W and 1508 (294) W in cycling were not different $(\mathrm{p}>0.05)$. The corresponding biomechanical efficiencies at MLSS were 17.6 (1.9)\% $v 22.1$ $(2.2) \% \quad(\mathrm{p} \leqslant 0.05)$ and $17.9(2.5) \% \quad v \quad 20.4$ $(3.8) \%(\mathrm{p}>0.05)$ at peak workload.

Independently of the type of exercise, correlations $(p \leqslant 0.05)$ were found between MLSS workload and peak workload $(r=0.88$, $\mathrm{p} \leqslant 0.001, \mathrm{y}=1.34 \mathrm{x}-194.4)$, and between MLSS oxygen uptake and peak oxygen uptake (fig 3).

\section{Discussion}

In young, not highly specialised athletes with similar training methods over 1-2 years, the MLSS was intraindividually lower in rowing than in cycle ergometry. In addition, the experiments showed similar results to those for top rank athletes performing only their specific type of exercise. ${ }^{2}$ Thus our results provide strong evidence that the motor pattern of exercise and not other previously discussed modulators, such as subject variation and specific adaptation to exercise training, predominantly causes the observed interindividual divergence of MLSS.

In contrast with the MLSS, the workload at MLSS did not differ between rowing and cycle ergometry. Furthermore, the present data underline and extend results indicating that MLSS intensity expressed as a percentage of the peak workload did not differ between selected sports. ${ }^{2}$ However, it should be taken into consideration that, on traditional rowing ergometers, the body mass is moving backwards and forwards on a rolling seat during each stroke. The corresponding acceleration and deceleration forces cause an additional stroke rate dependent mechanical power output which is not measured. At stroke rates of about $30 / \mathrm{min}$, as in the present study, the corresponding additional power output is about $0.7 \mathrm{~W} / \mathrm{kg}$ body mass. ${ }^{19}{ }^{20}$ This would increase MLSS workload and peak workload considerably to about $228 \mathrm{~W}$ and 329 W. Metabolic power can be calculated from oxygen uptake and net lactate production, ${ }^{16}$ and biomechanical efficiency from MLSS workload, peak workload, and the corresponding metabolic rates. On the basis of the latter, the contribution to the above correction of the measured rowing workloads would increase the biomechanical efficiency of rowing ergometry from about $18 \%$ to about $22 \%$, which is similar to the observed efficiency of cycling. Thus the latter consideration of indirectly measured fractions of mechanical power in rowing would result in higher $(\mathrm{p} \leqslant 0.05)$ workload at MLSS and peak workload in rowing compared with cycle ergometry but does not have any effect on the corresponding relative exercise intensity.

The MLSS represents the highest equilibrium between lactate appearance and disappearance in the intravascular compartment, which is underlined by the fact that more than $99 \%$ of the metabolic power is provided aerobically in both rowing and cycling and that the corresponding fraction of anaerobic lactate energy is more or less exclusively generated during the initial 5-10 minutes of constant workload (fig 1). However, BLC and thus MLSS does not represent the metabolic state of selected muscles. ${ }^{21}{ }^{22}$ During exercise, lactate production and elimination may be controlled by the mass of the muscle being exercised. ${ }^{23}$ Other organs that contribute to lactate metabolism, such as heart, ${ }^{24}$ liver, ${ }^{25}$ and kidneys, ${ }^{26}$ have a smaller tissue mass or reduced perfusion compared with the skeletal muscle during exercise. $^{27}$

Lactate production and oxidative lactate clearance is determined by factors such as mass of the primarily engaged skeletal muscle, pattern of intermuscular coordination, and fibre recruitment. ${ }^{28-31}$ These factors appear to be affected by the motor pattern of exercise. Rowing is a combination of leg, trunk, and arm work, which represents more than $85 \%$ of the total muscle mass. ${ }^{19}$ This is considerably more than the corresponding muscle mass in cycling, which is dominated by leg work. The fact that different levels of MLSS appeared at similar levels of oxygen uptake, relative exercise intensity, and heart rate indicates that, in rowing, the power output per unit of muscle mass is less than in cycling. Assuming that rowing power output is generated by about $85 \%$ of the total muscle mass and that the total muscle mass represents about $40 \%$ of the body mass, the observed performance would result in a relative power output per $\mathrm{kg}$ muscle mass of $9.6 \mathrm{~W} / \mathrm{kg}$ at MLSS and $13.9 \mathrm{~W} / \mathrm{kg}$ at peak workload in rowing ergometry. In cycling, which requires work by about $60 \%$ of the total muscle mass, the corresponding relative workloads would be $12.2 \mathrm{~W} / \mathrm{kg}$ at MLSS and $17.8 \mathrm{~W} / \mathrm{kg}$ at peak workload. In cycling, this muscular exercise intensity is $25-30 \%$ higher than the corresponding value in rowing even if the additional rolling work during rowing ergometry is taken into consideration. This underlines and extends previous results showing that the power output per unit muscle mass and the BLC are lower if the mass of the primarily engaged muscle increases. ${ }^{32}$ 
The latter is supported by observations that, at a given level of oxygen uptake and similar total glycogen consumption, ${ }^{33-35}$ the glycogen loss per muscle fibre is lower in running than in cycling ${ }^{33}$ and that, at similar exercise intensities, muscular glycolysis is higher during arm cranking than during cycling. ${ }^{36}$ In addition, glycogen uptake by the legs is reduced if arm exercise is added to the cycle ergometer work. ${ }^{37}$ Also the force and dynamics of muscular engagement are specific qualities of selected tests. Biomechanical analyses comparing rowing on a boat and rowing on an ergometer ${ }^{20}$ and kinematic data of cycling at different pedalling rates $^{38}$ indicated corresponding divergences in force and dynamics per stroke. In cycling, the driving force per stroke and its rating increase at lower pedalling rates. ${ }^{39}{ }^{40}$ In addition, low pedalling rates cause intensive upper body work. Such variations in the motor pattern of exercises may affect MLSS because glycolysis and pyruvate oxidation depend on the energetic demands of exercise. ${ }^{30} 31$

Glycolysis can be expected to increase more or less sigmoidally with relative exercise intensity. $^{30} 31$ In contrast, the relation between relative exercise intensity and oxidative metabolism is almost linear. ${ }^{41}$ During exercise, lactate production and elimination are determined by exercise intensity and mass of the muscles engaged. In a given mode of exercise, the primarily engaged muscles work with higher exercise intensity than the assisting muscles. If the primarily engaged muscle mass is small, the complementary muscular work is performed by a large muscle mass exercising at low relative intensity. According to the lactate shuttle hypothesis, ${ }^{28} 29$ a large assisting muscle mass may be able to use lactate as fuel for oxidative metabolism if, in the small primarily engaged muscle mass, lactate production is higher than lactate oxidation. Under these conditions, a steady state of BLC may indicate an overall balance between lactate appearance and disappearance in spite of net lactate production by the primarily engaged muscles. With increasing mass of the primarily engaged muscle, the difference in relative exercise intensity between the latter and the assisting muscle mass may decrease. With respect to a steady state of BLC, this may diminish the capacity to compensate net lactate production of the primarily engaged muscles. This may explain why, compared with cycling, lower levels of MLSS in rowing appear to be combined with similar or even higher BLCs at peak workload, indicating a more or less similar fraction of $15 \%$ anaerobic lactate energy in rowing and cycling.

The highest MLSS values are observed in speed skating ${ }^{2}{ }^{42}$ and arm ergometry. ${ }^{43}$ Obviously, in arm ergometry the mass of the primarily engaged muscles is lower than in cycling. Low pedalling rates and rowing ergometry intensifying arm work resulted in the lowest MLSS values. ${ }^{27}$ This seems to be in line with observations that exercise by small muscle masses such as arm ergometry result in higher glycolytic rates of the working muscles possibly through greater sympathoadrenal stimulation and coactivation..$^{36} 37445$ Therefore the level of MLSS may be negatively related to the mass of the primarily engaged muscles. Consequently, the ratio between the mass of the primarily engaged and assisting muscles may modulate the dynamic steady state between lactate production and elimination and thus the MLSS.

In conclusion, this study supports the hypothesis that the MLSS predominantly depends on the motor pattern of exercise. The differences in MLSS observed during different types of exercise seem to be caused by differences in mass of the primarily engaged muscles. With respect to the latter, MLSS seems to correspond to task specific levels of power output per unit of working muscle. This appears to cause task specific BLC limits, allowing an overall equilibrium between glycolytic production and oxidative consumption of lactate. The latter may explain why the MLSS is negatively related to the mass of the primarily engaged muscles.

1 Bang $\mathrm{O}$. The lactate content of blood during and after muscular exercise in men. Scand Arch Physiol 1936;74(suppl 10):51-82.

2 Beneke R, von Duvillard SP. Determination of maximal lactate steady state response in selected sports events. Med Sci Sports Exerc 1996;28:241-6.

3 Hartmann U, Mader A, Petersmann G, et al. Verhalten von Herzfrequenz und Laktat während ruderspezifischer Trainingsmethoden. Deutsche Zeitschrift für Sportmedizin 1989; 40:200-12.

4 Mader A. Evaluation of the endurance performance of marathon runners and theoretical analysis of test results. $\mathcal{F}$ Sports Med Phys Fitness 1991;31:1-19.

5 Urhausen A, Coen B, Weiler B, et al. Individual anaerobic threshold and maximum lactate steady-state. Int $\mathcal{F}$ Sports Med 1993;14:134-9.

6 Wasserman K, McIlroy MB. Detecting the threshold of anaerobic metabolism in cardiac patients during exercise. Am 7 Cardiol 1964;14:844-52.

7 Beneke R. Anaerobic threshold, individual anaerobic threshold, and maximal lactate steady-state in rowing. Med Sci Sports Exerc 1995;27:863-7.

8 Heck H, Mader A, Hess G, et al. Justification of the 4-mmol/1 lactate threshold. Int $\mathcal{f}$ Sports Med 1985;6: $117-30$

9 Foster C, Thompson N. The physiology of speed skating. In: Casey MJ, Foster C, Hixson EG, eds. Winter sports medicine. Philadelphia: Davis FA Co, 1990;221-40.

10 Lavruskin VP, Ivanov VS, Andrjunin MA. Organizacija i kontrol' trenirovocnogo processa u kon'kobezcev-juniorov sbornoj komandy SSSR [Organisation and control of the raining process of junior class national team speed skaters]. Naucno-sportion 1996;3:5-11.

11 Beneke R, Heck H, Schwarz V, et al. Maximal lactate steady state during the second decade of age. Med Sci Sports Exerc state during the seco

12 Beneke R, Boldt F, Richter Th, et al. Laktatmessung in der Sportmedizin: drei Geräte im Vergleich. Deutsche Zeitschrift für Sportmedizin 1994;45:60-64, 69.

13 Kawakami YD, Nozaki D, Matsuo A, et al. Reliability of measurement of oxygen uptake by a portable telemetric system. Eur F Appl Physiol 1992;65:409-14.

14 Lucia A, Fleck SJ, Gotshall RW, et al. Validity and reliability of the Cosmed K2 ${ }^{\circledR}$ instrument. Int $\mathcal{F}$ Sports Med 1993;14: $380-6$.

15 Beneke R, Sievers U, Buschkow S, et al. Portables Spirometrie-Telemetrie-System vs. Laborspirometer; Gerätevergleich unter Laborbedingungen. Deutsche Zeitschrift für Sportmedizin 1995;46:403-8.

16 Beneke R, Meyer M. Walking performance and economy in chronic heart failure patients pre and post exercise training. Eur f Appl Physiol 1997;75:246-51.

17 di Prampero PE. Energetics of muscular exercise. Rev Physiol Biochem Pharmacol 1981;89:144-222.

18 Stegemann J. Leistungsphysiologie: physiologische Grundlagen der Arbeit und des Sports. Stuttgart: Georg Thieme Verlag, 1991:56-69.

19 Mader A, Hartmann U, Hollmann W. Der Einfluß der Ausdauer auf die 6-minütige maximale anaerobe Arbeitskapazität eines Eliteruderers. In: Steinacker JM, eds. Rudern. perlin: Springer, 1988:62-78.

20 Nolte V, Klauk J, Mader A. Vergleich biomechanischer Merkmale der Ruderbewegung auf dem GjessingErgometer und im fahrenden Boot. In: Heck H, Hollmann W, Liesen H, et al, eds. Sport: Leistung und Gesundheit. Köln: Deutscher Ärzte-Verlag, 1983:513-18. 
21 Bergman BC, Wolfel EE, Butterfield GE, et al. Active muscle and whole body lactate kinetics after endurance training cle and whole body lactate kinetics after end

22 Brooks GA, Wolfel EE, Butterfield GE, et al. Poor relationship between arterial [lactate] and leg net release during exercise at $4300 \mathrm{~m}$ altitude. Am F Physiol 1998;275:R1192201

23 Walsh ML, Banister EW. Possible mechanisms of the anaerobic threshold. Sports Med 1988;5:269-302.

24 Keul J, Doll E, Stein H, et al. Über den Stoffwechsel des Herzens bei Hochleistungssportlern. I. Die Substratversorgung des trainierten Herzens in Ruhe, während und nach körperlicher Arbeit. Zeitschrift für Kreislaufforschung 1966;55:190-215.

25 Wasserman DH, Connolly CC, Pagliassotti J. Regulation of hepatic lactate balance during exercise. Med Sci Sports Exerc 1991;23:912-19.

26 Yudkin J, Cohen RD. The contribution of the kidney to the removal of a lactic acid load under normal and acidotic conditions in the conscious rat. Clin Sci Mol Med 1975;48: conditions

27 Rowell LB. Human cardiovascular adjustments to exercise and thermal stress. Physiol Rev 1974;54:75-159.

28 Brooks GA. Lactate production under fully aerobic conditions: the lactate shuttle during rest and exercise. Fed Proc 1986;45:2924-9.

29 Brooks GA. The lactate shuttle during exercise and recovery. Med Sci Sports Exerc 1986;18:360-8.

30 Mader A. Energiestoffwechselregulation, Erweiterung des theoretischen Konzepts und seiner Begründung: Nachweis der praktischen Nützlichkeit der Simulation des Energiestoffwechsels. In: Mader A, Allmer H, eds. Brennpunkte der Sportwissenschaft. Computersimulation: Möglichkeiten zur Theoriebildung und Ergebnisinterpretation. Sankt Augustin: Academica Verlage, 1994:124-62.

31 Mader A, Heck H. A theory of the metabolic origin of "anaerobic threshold". Int F Sports Med 1986;7(suppl 1): $45-65$.

32 Hoffmann MD, Kassay KM, Zeni AI, et al. Does the amount of exercising muscle alter the anaerobic demand of dynamic exercise? Eur F Appl Physiol 1996;74:541-7.
33 Costill DL, Sparks K, Gregor R, et al. Muscle glycogen utilization during exhaustive running. $₹$ Appl Physiol 1971;31: 353-6.

34 Coyle EF, Coggan AR, Hopper MK, et al. Determinants of endurance in well-trained cyclists. $\mathcal{F}$ Appl Physiol 1988;64: 2622-30.

35 Hermansen L, Hultman E, Saltin B. Muscle glycogen during prolonged severe exercise. Acta Physiol Scand 1967; 71:129-39.

36 Ahlborg G, Jensen-Urstad M. Metabolism in exercising arm vs. leg muscle. Clin Physiol 1991;11:459-68.

37 Richter EA, Kienes B, Saltin B, et al. Skeletal muscle glucose uptake during dynamic exercise in humans: role of muscle mass. Am f Physiol 1988;254:E555-61.

38 Widrick JJ, Freedson PS, Hamill J. Effect of internal work on calculation of optimal pedalling rates. Med Sci Sports Exerc 1992;24:376-82

39 Löllgen H. Zur Bedeutung der Tretgeschwindigkeit in der klinischen Ergometrie. Habilitationsschrift, Medizinische klinischen Ergometrie. Habilitationsschrift, ${ }^{2}$

40 von Duvillard SP, Hagan RD. Independence of ventilation and blood lactate responses during graded exercise. Eur $\mathcal{F}$ appl Physiol 1994;68:298-302.

Appl Physiol 1994;68:298-302.
41 Donovan CM, Brooks GA. Endurance training affects lactate clearance, not lactate production. Am $\mathcal{f}$ Physiol 1983;244:E83-92.

42 Beneke R, Boldt F, Meller W. Das maximale Laktat-SteadyState im Eisschnellauf. In: Bernett P, Jeschke D, eds. Sport und Medizin, Pro und Contra. München, Bern, Wien, San Francisco: Zuckschwerdt, 1991:766-7.

43 Krüger J, Schnettler S, Heck H, et al. Relationship between rectangular, triangular increasing work load and maximal lactate steady state on the crank ergometer. In: Hermans GPH, Mosterd WL, eds. Sports, medicine and health. Amsterdam: Excerpta Medica, 1990.

44 Weltman A, Wood CM, Womack CJ, et al. Catecholamine and blood lactate response to incremental rowing and running exercise. 7 Appl Physiol 1994;76:1144-9.

45 Schneider DA, McLellan TM, Gass GC. Plasma catecholamine and blood lactate responses to incremental arm and leg exercise. Med Sci Sports Exerc 2000;32:608-13.

\section{Take home message}

The highest BLC representing an equilibrium between lactate production and elimination is termed maximal lactate steady state (MLSS). MLSS seems to decrease with increasing mass of the primarily engaged muscles. This indicates that task specific levels of MLSS occur at distinct levels of power output per unit of primarily engaged muscle mass. 